\title{
A study of causes of respiratory distress in neonates presenting within 72 hours
}

\author{
Mehta $A^{1}$, Pratap $D^{2}$, Kushwaha K.P ${ }^{3}$, Singh $A^{4}$, Sharma $B^{5}$, Mittal $\mathbf{M}^{6}$ \\ ${ }^{1}$ Dr Anita Mehta, Associate Professor, ${ }^{2}$ Dr. Divya Pratap, Senior Resident, ${ }^{3}$ Dr. K P Kushwaha, Ex Prof \& Head, ${ }^{4}$ Dr. \\ Abhishek Singh, Lecturer, ${ }^{5}$ Dr. Bhoopendra Sharma, ${ }^{6}$ Dr. Mahima Mittal, Associate Professor; all authors are affiliated \\ with Department of Pediatrics, B.R.D Medical College, Gorakhpur, UP, India.
}

Address for Correspondence: Dr. Anita Mehta, Associate Professor, Dept of Pediatrics, BRD Medical College, Gorakhpur, UP, India. Email: 25anitamehta@gmail.com

\begin{abstract}
Objectives: to determine the prevalence of known causes of respiratory distress (RD) in neonates within 72 hours and their immediate clinical outcome. Material and methods: All inborn and out born neonates admitted in Neonatal Unit of Pediatric Department of BRD medical College, Gorakhpur who developed RD within 72 hours of life were studied. Neonates with birth weight less than 1000 grams and less than 28 wks of gestation were excluded from the study. Result: Out of 1032 neonates screened, 330 neonates (31.98\%) admitted with features of RD. Male neonates were two third (67.88\%) with M: F ratio of 2.1: 1 and two third of them preterm. Sepsis with pneumonia was found to be the most common cause of RD in neonates (46.36\%) followed by hypoxic ischemic encephalopathy (19.09\%), hyaline membrane disease(HMD) (13.13\%), meconium aspiration syndrome (11.52\%), transient tachypnea of neonates (7.27\%) and congenital heart disease (2.42\%). Eighty five percent neonates were delivered outside, out of these $55.2 \%$ were delivered at home by untrained birth attendant. Overall mortality was seen in $31.52 \%$, which was highest in HMD (52.3\%) and highest (38.9\%) amongst neonates of gestational age $<37$ weeks. Two twenty nine $(69.39 \%)$ neonates of RD were kept on ventilator, out of them $99(30.0 \%)$ expired, maximum mortality was seen in HMD. Conclusion: Sepsis with pneumonia was the common cause of admission with features of RD. Mostly these neonates were preterm, delivered outside mainly at home, weighing $<2500$ gm with common responsible organism was Klebsiela. Highest mortality was seen in HMD.
\end{abstract}

Keywords: respiratory distress, sepsis with pneumonia, hyaline membrane disease(HMD), neonates, mortality

\section{Introduction}

Respiratory distress (RD) in neonates is one of the important clinical entities for admission in Neonatal Intensive Care Unit (NICU), seen in approximately 6.712 percent of neonates [1,2]. The prevalence of $\mathrm{RD}$ varies with gestational age, $30 \%$ among preterm, and $20 \%$ among post terms to $4 \%$ in term babies [3]. The etiology of RD in neonates is varied, and respiratory causes include hypoxic ischemic encephalopathy (HIE) transient tachypnea of neonates (TTNB), hyaline membrane disease (HMD), meconium aspiration syndrome (MAS), pneumonia, pneumothorax and diaphragmatic hernia. Non respiratory causes include cardiac failure, septicemia, metabolic disorders, renal failure, renal tubular acidosis, anemia, polycythemia, meningitis/ intracranial bleed and miscellaneous causes.

Manuscript received: $20^{\text {th }}$ December 2016

Reviewed: $27^{\text {th }}$ December 2016

Author Corrected: $5^{\text {th }}$ January 2017

Accepted for Publication: $13^{\text {th }}$ January 2017
There has been tremendous advancement in the management of $\mathrm{RD}$ which has improved the outcome in these neonates, like mechanical ventilation with different modes such as CPAP, ultra high-frequency jet ventilation, liquid ventilation; surfactant replacement therapy; extra corporeal membrane oxygenation and sophisticated equipment for monitoring. Despite these advancement, $\mathrm{RD}$ is responsible for $40-50 \%$ of all the perinatal deaths [4] .

Knowing the fact that, neonates with RD are 2-4 times more likely to die than those without RD [5] and as there is lack of literature on spectrum of $\mathrm{RD}$ in Gorakhpur region, the aim of present study was to know the spectrum of RD and accordingly can plan for preventive measures in our setup and at the same time we can prevent the morbidity of respiratory distress. Therefore this study has been planned with following objectives: 
1 To determine the prevalence of known causes of RD in neonates brought to our NICU with symptoms suggestive of RD within 72 hours.

2 To know the immediate clinical outcome of RD in neonates.

\section{Material and Methods}

This cross sectional study was carried out in the department of Pediatrics, B.R.D. Medical College, Gorakhpur from April 2015 to July 2015. The study protocol was approved by the institutional ethics committee.

Well informed written consent in local language was taken from mothers/ guardians of each infant, ensuring their full confidentiality. A total of 1032 admitted neonates screened from NICU of Department of Pediatric, BRD Medical College, Gorakhpur.

Both inborn and out born neonates within $72 \mathrm{hrs}$ of life admitted to NICU with RD were included in study. Neonate's birth weight less than 1000 gms, gestation age less than 28 wks and with multiple congenital malformations were excluded from the study. RD [6] was diagnosed by presence of at least 2 of the following on two consecutive examinations at least 1 hour apart:

1. Respiratory rate of $>60 / \mathrm{min}$ or more

2.Chest retraction (subcostal indrawing, xiphoid retraction, suprasternal indrawing)

3. Expiratory grunt/groaning
A detailed history and detailed examination of each neonates was recorded on a predesigned semi structural Performa on the day of admission. Severity of RD was assessed by Silverman \& Anderson Clinical Score [7] and maturity of neonates was assessed by New Ballard scoring system [8].

Etiological diagnosis of RD was made on clinical ground and it was confirmed by related investigations like Sepsis screen, Shake test, Blood culture and Drug Sensitivity, Chest X Ray PA view, blood biochemical tests (sugar, $\mathrm{Na}, \mathrm{K}, \mathrm{Ca}$, urea, creatinine), Echocardiography, EEG, ABG and USG of cranium.

Neonates were managed according to Standard Management Protocol of Neonates. Neonates were oxygenated by using nasal prong or CPAP and ventilator was started in those who required ventilator support. They were weaned of the ventilator when showed clinical improvements. Surfactant was used in patients of HMD.

Daily monitoring of neonates was done regarding development of new signs and symptoms, oxygen therapy, ventilator use and surfactant therapy till discharge. Mortality, complication during the hospital stay and any need of surgical intervention was recorded.

Statistical analysis- Data was collected and analyzed using SPSS version 16. P value of $<0.05$ was considered significant.

\section{Result}

Out of 1032 neonates screened, 330 neonates (31.98\%) admitted in our NICU with features of RD. Male neonates were more $(n=224,67.88 \%)$ than female $(n=106,32.1 \%)$ with $M: F$ ratio of $2.1: 1$.

Table 1 showing etiology of RD in neonates. In our study Sepsis with pneumonia was found to be the most common cause of RD in neonates $(\mathrm{n}=153,46.36 \%)$ followed by HIE $(\mathrm{n}=63,19.09 \%)$, HMD $(\mathrm{n}=44,13.13 \%)$, MAS $(\mathrm{n}=38,11.52 \%)$, TTNB (n=24, 7.27\%) and CHD (n=8, 2.42\%).

Table-1: Etiology of RD in neonates.

\begin{tabular}{|c|c|c|}
\hline Diagnosis & \multicolumn{2}{|c|}{ Total Cases, $\mathbf{n}=\mathbf{3 3 0}$} \\
\hline & $\mathbf{n}$ & 46.36 \\
\hline Sepsis with Pneumonia & 153 & 13.13 \\
\hline Hyaline membrane disease(HMD) & 44 & 11.52 \\
\hline Meconium aspiration syndrome (MAS) & 38 & 7.27 \\
\hline Transient tachypnea of neonates (TTNB) & 24 & 19.09 \\
\hline HIE (Hypoxic Ischemic Encephalopathy) & 63 & 2.42 \\
\hline Congenital Heart Disease (CHD) & 8 & \\
\hline
\end{tabular}


When RD was compared with place of delivery, RD was more common in outside deliveries ( $\mathrm{n}=281,85.15 \%)$, out of these $55.2 \%$ were delivered at home by untrained birth attendant. This correlation was more important for Sepsis with pneumonia, where $92.6 \%$ neonates were delivered outside.

Table 2 showing birth weight \& gestational age wise distribution of causes of RD. Maximum cases $(n=158,47.88 \%)$ of $\mathrm{RD}$ were of $>2500 \mathrm{gm}$ birth weight and $40.3 \%(\mathrm{n}=133)$ cases were between 1500-2499 gm. When birth weight was analyzed for the development of different causes of RD, we found that more than $50 \%$ neonates of Sepsis with Pneumonia are of $>2500 \mathrm{gm}$. Maximum neonates ( $\mathrm{n}=21,47.73 \%$ ) of HMD were between $1000-1499$ grams, $12(50.0 \%)$ neonates of TTNB were of $>2500 \mathrm{gm}$ and 34 (53.97\%) neonates of HIE were between 1500- $2499 \mathrm{gm}$.

Table-2: Birth weight \& gestational age wise distribution of causes of RD.

\begin{tabular}{|c|c|c|c|c|c|c|c|}
\hline Birth weight & $\begin{array}{l}\text { Sepsis with } \\
\text { Pneumonia } \\
\text { n=153 (\%) }\end{array}$ & $\begin{array}{c}\text { HMD } \\
\text { n=44 (\%) }\end{array}$ & $\begin{array}{c}\text { MAS } \\
\mathbf{n}=\mathbf{3 8}(\%)\end{array}$ & $\begin{array}{c}\text { TTNB } \\
\text { n=24 (\%) }\end{array}$ & $\begin{array}{c}\text { HIE } \\
n=63(\%)\end{array}$ & $\begin{array}{c}\text { CHD } \\
\mathrm{n}=\mathbf{8}(\%)\end{array}$ & $\begin{array}{c}\text { Total } \\
\mathbf{n}=\mathbf{3 3 0}(\%)\end{array}$ \\
\hline $1000-1499 \mathrm{gm}$ & 11(7.19) & $21(47.73)$ & 0 & $4(16.17)$ & $1(1.59)$ & $2(25.0)$ & $39(11.82)$ \\
\hline 1500 - $2499 \mathrm{gm}$ & $62(40.52)$ & $14(31.38)$ & $14(36.84)$ & $8(33.33)$ & $34(53.97)$ & $1(12.5)$ & $133(40.30)$ \\
\hline$>2500 \mathrm{gm}$ & $80(52.29)$ & $9(20.45)$ & $24(63.16)$ & $12(50.0)$ & $28(44.44)$ & $5(62.5)$ & $158(47.88)$ \\
\hline $\begin{array}{c}\text { Mean birth } \\
\text { weight }\end{array}$ & $2400 \mathrm{gm}$ & $1600 \mathrm{gm}$ & $2640 \mathrm{gm}$ & $2290 \mathrm{gm}$ & $2360 \mathrm{gm}$ & $2260 \mathrm{gm}$ & \\
\hline \multicolumn{8}{|l|}{ Gestational age } \\
\hline$<37$ weeks & $136(88.89)$ & $44(100)$ & 0 & 0 & $46(73.02)$ & $2(25,0)$ & $228(69.09)$ \\
\hline 37 - 42 weeks & $17(11.11)$ & 0 & $22(57.89)$ & $24(100)$ & $17(26.98)$ & $6(75.0)$ & $86(26.06)$ \\
\hline$>42$ weeks & 0 & 0 & $16(42.11)$ & 0 & 0 & 0 & $16(4.85)$ \\
\hline
\end{tabular}

When causes of RD was compared with gestation age, we found that majority of neonates of Sepsis with pneumonia were less than 37 weeks of gestation $(136,88.89 \%)$.

All neonates with Hyaline membrane disease (HMD) were pre term while all the neonates with TTNB were term. In our study HIE was more common (73.02\%) in preterm.

Silverman \& Andersen Score was compared with various causes of RD (Table 3) and we found that maximum (7-10) Silverman's score was seen in HMD (54.54\%), thus presented with impending respiratory failure and required mechanical ventilation. Mild RD (score $<3$ ) was seen in TTNB (66.67\%).

Table-3: Assessment of Silverman Score in various causes of RD.

\begin{tabular}{|c|c|c|c|c|c|c|c|}
\hline $\begin{array}{c}\text { Silverman } \\
\text { score }\end{array}$ & $\begin{array}{c}\text { Pneumonia } \\
\mathbf{n = 1 5 3}(\mathbf{\%})\end{array}$ & $\begin{array}{c}\text { HMD } \\
\mathbf{n = 4 4}(\mathbf{\%})\end{array}$ & $\begin{array}{c}\text { MAS } \\
\mathbf{n = 3 8}(\mathbf{\%})\end{array}$ & $\begin{array}{c}\text { TTNB } \\
\mathbf{n = 2 4}(\mathbf{\%})\end{array}$ & $\begin{array}{c}\text { HIE } \\
\mathbf{n = 6 3}(\%)\end{array}$ & $\begin{array}{c}\text { CHD } \\
\mathbf{n = 8}(\%)\end{array}$ & $\begin{array}{c}\text { Total } \\
\mathbf{n}=\mathbf{( \% )}\end{array}$ \\
\hline$<3$ & $54(35.29)$ & $12(27.27)$ & $16(42.11)$ & $16(66.67)$ & $14(22.22)$ & $6(75.0)$ & $118(35.76)$ \\
\hline $4-6$ & $60(39.22)$ & $8(18.18)$ & $15(39.47)$ & $8(33.33)$ & $20(31.75)$ & - & $111(33.64)$ \\
\hline $7-10$ & $42(27.45)$ & $24(54.54)$ & $7(18.42)$ & - & $29(46.03)$ & $2(25.0)$ & $101(30.61)$ \\
\hline mean (SD) & $5(2.55)$ & $5.7(2.8)$ & $4.56(2.5)$ & $3.25(1.17)$ & $5.8(2.71)$ & $5.92(3.21)$ & \\
\hline
\end{tabular}

Lab investigations were done to diagnose the etiology of $\mathrm{RD}$, among them blood culture was done to know the causative organism (Table 4). In our study commonest organism was Klebsiela ( $n=11,29.73 \%)$ followed by Staph. aureus ( $n=9$, $24.32 \%$ ) and other organisms i.e. E.coli, Pseudomonas and Coagulase negative Staph were equally distributed. 
Table-4 Common organism found in blood culture positive cases.

\begin{tabular}{|c|c|c|c|c|c|}
\hline Organisms & $\begin{array}{c}\text { Pneumonia } \\
\mathbf{2 6}(\mathbf{\%})\end{array}$ & $\begin{array}{c}\text { HMD } \\
\mathbf{n = 3}\end{array}$ & $\begin{array}{c}\text { HIE } \\
\mathbf{n = 6}\end{array}$ & $\begin{array}{c}\text { MAS } \\
\mathbf{n = 2}\end{array}$ & $\begin{array}{c}\text { Total } \\
\mathbf{n}=\mathbf{3 7}\end{array}$ \\
\hline Kleibsella & 8 & 2 & - & 1 & $10(29.73)$ \\
\hline S. aureus & 5 & 1 & 3 & - & $8(24.32)$ \\
\hline E.coli & 6 & - & - & - & $6(16.22)$ \\
\hline pseudomonas & 7 & - & - & - & $7(18.92)$ \\
\hline coag neg staph. & - & - & 5 & 1 & $6(16.22)$ \\
\hline
\end{tabular}

Table 5 showing ventilator support given among neonates of RD. CPAP was commonly ( $\mathrm{n}=188,58.4 \%)$ used for the management of RD. Neonates kept on mechanical ventilation for HMD ( $n=26,59 . \%)$, CHD ( $n=2,25.5 \%), H I E(n=20$, $31.75 \%)$ and Sepsis with pneumonia $(n=41,26.8 \%)$ with a total neonates of $105(34.8 \%)$.

Table-5: Ventilator support given among different causes of RD.

\begin{tabular}{|c|c|c|c|c|}
\hline Study Group & CPAP & MV & $\begin{array}{c}\text { Ventilator } \\
\text { support given } \\
\mathbf{N}=\mathbf{( \% )}\end{array}$ & $\begin{array}{c}\text { Mortality on } \\
\text { ventilator support } \\
\mathbf{N}=\mathbf{( \% )}\end{array}$ \\
\hline $\begin{array}{c}\text { Sepsis with } \\
\text { Pneumonia } \mathrm{n}=153(\%)\end{array}$ & $53(34.64)$ & $41(26.80)$ & $94(61.44)$ & $24(25.53)$ \\
\hline HMD $\mathrm{n}=44(\%)$ & $30(68.18)$ & $9(20.45)$ & $39(88.63)$ & $32(72.73)$ \\
\hline MAS $\mathrm{n}=38(\%)$ & $24(65.16)$ & $7(18.42)$ & $31(81.58)$ & $19(61.29)$ \\
\hline TTNB $\mathrm{n}=24(\%)$ & $16(66.67)$ & 0 & $16(66.67)$ & 0 \\
\hline HIE $\mathrm{n}=63(\%)$ & $23(36.51)$ & $20(31.75)$ & $43(68.25)$ & $22(51.16)$ \\
\hline CHD $\mathrm{n}=8(\%)$ & $4(50.5)$ & $2(25.5)$ & $6(75.5)$ & $2(33.33)$ \\
\hline Total $\mathrm{n}=330(\%)$ & $150(45.45)$ & $79(23.9)$ & $229(69.39)$ & $99(30.0)$ \\
\hline
\end{tabular}

Table 6 is showing outcome of infants at the time of discharge. Overall mortality was seen in 104(31.51\%) neonates. When mortality was analyzed according to causes of RD high mortality was seen in HMD $(n=26,59.09 \%)$. In other causes of RD, $28.76 \%(n=44)$ of Sepsis with pneumonia, $21.5 \%(n=8)$ of MAS, $36.51 \%(n=23)$ of HIE, and $37.5 \%(n=3)$ of CHD were expired.

Table-6: Outcome of infants at the time of discharge according to causes of RD

\begin{tabular}{|c|c|c|c|c|c|c|c|}
\hline $\begin{array}{c}\text { Causes of } \\
\text { RD }\end{array}$ & $\begin{array}{c}\text { Pneumonia } \\
\mathbf{n = 1 5 3 ( 4 6 . 3 6 \% )}\end{array}$ & $\begin{array}{c}\text { HMD } \\
\mathbf{4 4 ( 1 3 . 1 3 \% )}\end{array}$ & $\begin{array}{c}\text { MAS } \\
\mathbf{3 8}(\mathbf{1 1 . 5 2} \%)\end{array}$ & $\begin{array}{c}\text { TTNB } \\
\mathbf{2 4}(\mathbf{7 . 2 7} \%)\end{array}$ & $\begin{array}{c}\text { HIE } \\
\mathbf{6 3}(\mathbf{1 9 . 0} \%)\end{array}$ & $\begin{array}{c}\text { CHD } \\
\mathbf{8}(\mathbf{2 . 4 2} \%)\end{array}$ & $\begin{array}{c}\text { Total } \\
\mathbf{3 3 0}(\mathbf{1 0 0} \%)\end{array}$ \\
\hline $\begin{array}{c}\text { Expired } \\
\text { cases }\end{array}$ & $44(28.76)$ & $26(59.09)$ & $8(21.05)$ & $0(0)$ & $23(36.51)$ & $3(37.5)$ & $104(31.52)$ \\
\hline Survived & $109(71.24)$ & $18(40.9)$ & $30(78.95)$ & $24(100)$ & $40(63.49 \%)$ & $5(62.5)$ & $226(69.09)$ \\
\hline
\end{tabular}

When mortality was compared with sex, birth weight and gestational age, we found that high mortality was seen in birth weight 1000-1499 ( $n=32,82.05 \%)$, Sex wise there was no much difference in mortality. Maximum number (88, 38. 59\%) of cases was expired in $<37$ weeks of gestation.

Ventilator support (CPAP and MV) and mortality in ventilated neonates according to causes of RD is shown in Table 5. Ventilator support was given in Sepsis with pneumonia, HMD, MAS, TTNB, HIE, and in CHD neonates in 94(61.44\%) $(66.14 \%), 39(88.63 \%), 31(81.58 \%), 16(66.67 \%), 43(68.25 \%)$ and $6(75.5 \%)$ neonates respectively. Highest mortality $(\mathrm{n}=32,72.73 \%)$ on ventilator was seen in HMD. In TTNB no neonate on ventilator was expired. 


\section{Discussion}

In this hospital based cross sectional study we analyzed the spectrum of RD in neonates who admitted in NICU within $72 \mathrm{hrs}$ of life. In the present study, $31.98 \%$ of all the admissions during the study period were found to have RD. Other authors [9-11] have reported the incidence in the range of $29.2 \%-34.1 \%$, few [4,12] as low as $13.7 \%-15.15 \%$ and Zaazou M. H et a [13] reported up to $88.4 \%$ incidence of $\mathrm{RD}$ in their studies. This varied incidence of RD may be because of different source population, varied risk factors, referral practices in that area, and mode of transportation, different selection criteria and the gestational age of neonates.

In our study male $(67.88 \%)$ were more than female for development of RD, which was also reported by other authors $[5,11,14]$. Male female ratio was 2.1:1 which is similar to other author [15]. In our study M: F ratio was $>2$ for Pneumonia, MAS and CHD. Majority (68.8\%) were preterm, in other study [9-13] also more than two third neonates were preterm.

We found $85.15 \%$ of $\mathrm{RD}$ neonates were delivered outside, out of these $55.2 \%$ were delivered at home by untrained birth attendant in unhygienic environment and transported in poor hygienic condition. This figure, exclusively for Sepsis with pneumonia, was $92.6 \%$ and $55.9 \%$ respectively and this could be a reason for high proportion of Sepsis with pneumonia cases in our study. Mathur et al also reported that $51 \%$ of $\mathrm{RD}$ neonates delivered at home and $68.7 \%$ of them developed pneumonia. In other studies [5,10,12,15-17] pneumonia cases were less, because maximum neonates delivered in hospital by trained personnel.

In our study Sepsis with pneumonia was the leading cause $(46.36 \%)$ of RD. Similar observation with maximum cases of pneumonia as a cause of RD was found by Thomas et al, (44\%), Mathur et al (68.7\%) and Misra PK et al(32.2\%). Other authors [1,10,12] found TTN as a common cause of RD in their study. In contrast, HMD was found to be commonest cause of RD by Rubalteli et al (46\%). Different authors found different proportions of causes of RD in their study.

This wide variation in proportion of causes of RD may be due to antenatal care in that community, availability of obstetricians including trained birth attendants, use of preventive measures during antenatal period, proportion of term and preterm deliveries, non uniform inclusion criteria, type of facilities in Institution and various other factors. In our study high proportion of pneumonia and HIE is probably due to the fact that this is a referral hospital situated in eastern UP, comparatively a backward area of two states. Poor antenatal care in periphery and higher number of referred cases with prolonged labor and complications also contributed to high incidence.

In our study for Sepsis with pneumonia cases, majority of them having birth weight $>2500$ gm $(52.29 \%)$ with mean birth weight 2400 grams and maximum (88.89\%) were preterm. Other authors $[10,16]$ have also reported that maximum cases of pneumonia in their study were preterm.

In Sepsis with pneumonia cases, sepsis screen was positive in $23 \%$ cases and blood culture was positive in $16.99 \%$ cases, which is lower than that reported by Mathur N B et al. Klebsiela (30.77\%) was commonest organism in Sepsis with pneumonia cases. Common bacterial isolates as Klebsiela is consistent with the earlier studies also [9,19-21]. National Neonatal Perinatal Database [6] also reported Klebsiela $s$ the commonest $(35,5 \%)$ organism for neonatal sepsis.

Overall mortality in our study was $31.51 \%$, which is similar to reported by other authors $[5,9,11,13]$. When mortality was analyzed according to causes of RD high mortality was seen in HMD (59.09\%). Other authors $[10,13]$ also reported higher mortality in HMD. In our study there was no mortality in TTNB, which is similar to other studies [11-13].

In our study mild, moderate and severe grades of RD neonates were equally distributed, which is against the other author [11] where maximum neonates were in moderate grade. Mortality was assessed according to severity of RD. In mild RD (<3) out of 118 neonates 10 (8.47\%) were expired, in moderate RD (4-6) out of 111 neonates $66(59.46 \%)$ and in severe RD (7-10) out of 101 neonates $36(35.64 \%)$ were expired. Other author [11] reported $6.38 \%, 9.38 \%$ and $49.85 \%$ mortality in mild, moderate and severe $\mathrm{RD}$ respectively.

Mortality was highest (38.59\%) amongst neonates of gestational age $<37$ weeks. A decreasing trend in mortality in RD was observed with increase in gestational age which is seen by earlier authors also $[1,5,15,23]$. Neonates with birth weight between 1000- 
$1499 \mathrm{gm}$ have highest mortality (82.05\%), which is similar to earlier studies $[1,15]$.

In our study majority of neonates of HMD and MAS needed ventilator support, other authors [ 10,13$]$ given ventilator support maximally in HMD. There was $100 \%$ survival in TTNB on ventilator support, other authors $[10,12,13,22]$ also shown similar report. In our study highest mortality $(72.73 \%)$ on ventilator was seen in HMD which is similar to other report $[10,13]$. This high figure of mortality of HMD could be because of intermittent use of surfactant in our NICU, because being a backward and poor area, parents most of the time cannot afford surfactant.

\section{Conclusion}

$\mathrm{RD}$ is the commonest problem encountered in neonatal ICU. Most common cause of RD is Sepsis with pneumonia. Mortality was very high in neonates with HMD and in those required mechanical ventilation. Proper antenatal care, prevention of preterm delivery, planned institutional delivery, prevention of infection and appropriate management of HMD may reduce the incidence of RD and neonatal mortality.

Funding: Nil, Conflict of interest: None initiated, Perission from IRB: Yes

\section{References}

1. Kumar A, Bhat BV. Epidemiology of respiratory distress of newborns. Indian J Pediatr. 1996 Jan-Feb; 63(1):93-8.

2. Thomas S, Verma IC, Singh M, Menon PS. Spectrum of respiratory distress syndrome in the newborn in North India: a prospective study. Indian J Pediatr. 1981 JanFeb;48(390):61-5.

3. Singh M. Care of the Newborn. 7th edi. Delhi: Sagar Publication; 2010. Respiratory disorder; p. 275-285.

4. Santosh S, Kumar K, Adarsha E. A Clinical Study of Respiratory Distress In Newborn and its Outcome. Indian Journal of Neonatal Medicine and Research. 2013; 1(1): 2-4.

5. Misra PK. Respiratory distress in newborn. A prospective study. Indian Pediatr. 1987 Jan;24(1):77-80.

6. NNPD network. National Neonatal Perinatal Database. Delhi, India. Report 2002-03.
7. Sachdeva A, Dutta AK, Jain MP. Respiratory distress in newborn: Advance in paediatrics; Medical publisher. 2012: 83-91.

8. Cloherty JP, Eichenwald EC, Hansen AR. The HighRisk Newborn: Anticipation, Evaluation, Management and outcome: Manual of neonatal care. 7th edi. Lippincott Williams and Wilkins; 2012. 74-77 p.

9. Mathur NB, Garg K, Kumar S. Respiratory distress in neonates with special reference to pneumonia. Indian Pediatr. 2002 Jun;39(6):529-37.

10. Haque A, Baki MA, Begum T, Akhter S, Begum S, Nahar N. Etiology of Respiratory Distress in Newborn in BIRDEM. Birdem Medical Journal Vol. 2013; 1(1) : 1922.

11. Bajad M, Goyal S, Jain B. Clinical profile of neonates with respiratory distress. Int J Contemp Pediatr 2016 3:1009-13.

12. Dutta A, Sinhamahapatra . K.T . Spectrum of respiratory distress in newborn: A study from a tertiary care hospital in Kolkata. The Child and newborn, 2011; 15 (2): $45-48$.

13. Zaazou M. H, Kamal M M, Ali R M, Hussieny N E, Sayed M E, Descriptive study of cases of respiratory distress in NICU in Ahmed Maher Teaching hospital. Medical Journal Cairo University. 2011; 79 (1): $\quad$ 44148.

14. Hjalmarson O. Epidemiology and classification of acute, neonatal respiratory disorders. A prospective study. Acta Paediatr Scand. 1981 Nov;70(6):773-83.

15. Khatua SP, Gangwal A, Basu P, Palodhi PK. The incidence and etiology of respiratory distress in newborn. Indian Pediatr. 1979 Dec;16(12):1121-6.

16. Thomas S, Verma IC, Singh M, Menon PS. Spectrum of respiratory distress syndrome in the newborn in North India: a prospective study. Indian J Pediatr. 1981 JanFeb;48(390):61-5.

17. Kumar P, Kumar R, Narang A. Spectrum of neonatal respiratory distress at PGI. Bul NNF 1999; 13: 8-11.

18. Rubaltelli FF, Dani C, Reali MF, Bertini G, Wiechmann L, Tangucci M, Spagnolo A. Acute neonatal respiratory distress in Italy: a one-year prospective study. 
Italian Group of Neonatal Pneumology. Acta Paediatr. 1998 Dec; 87 (12) : $\quad$ 1261-8.

19. Duke T. Neonatal pneumonia in developing countries. Arch Dis Child Fetal Neonatal Ed. 2005 May;90(3):F211-9.

20. Misra S, Bhakoo ON, Ayyagiri A, Katariya S. Clinical \& bacteriological profile of neonatal pneumonia. Indian J Med Res. 1991 Nov;93:366-70.
21. Singh M. Care of the Newborn. 4th edn. Delhi: Sagar Publications; 1991. Perinatal infection; p.154-176

22. Helve O., Andresson S., Kirjavainen T. and Pitkanen O.M.Improvement of lung compliance during post natal adaptation correlates with airway sodium transport. American Journal of Respiratory and Critical Care Medicine. 2006; 173: 448-52.

23. Singhi S, Singhi PD. Clinical signs in neonatal pneumonia. Lancet. 1990 Oct 27;336(8722):1072-3.

\section{How to cite this article?}

Mehta A, Pratap D, Kushwaha K.P, Singh A, Sharma B, Mittal M. A study of causes of respiratory distress in neonates presenting within 72 hours. J PediatrRes.2017;4(01):22-28.doi:10.17511/ijpr.2017.i01.05 